\title{
Biofuel From Cow Tallow: A Case Study
}

\author{
Ribwar K Abdulrahman \\ Mohammed H Zangana \\ Jafar A Ali \\ Rebwar Ibrahim Aziz \\ Rawaz M Karem \\ Balen M. Hussain
}

Faculty of Engineering, Koya University, Kurdistan Region of Iraq

doi: 10.19044/esj.2016.v12n6p299 URL:http://dx.doi.org/10.19044/esj.2016.v12n6p299

\begin{abstract}
The global demand for energy in recent decade has been dramatic. Indeed, several oil and gas reservoirs around the world are depleted every day. Moreover, the fossil fuels for example, petroleum emitted huge quantities of toxic gases to the environment. Therefore, the passive environmental consequences of fossil fuels and the bother about fossil fuel supplies have encouraged the investigation for renewable biofuels. Thus, this work is objective to produce a biodiesel fuel from residual cow tallow that produced every day at Koya city slaughterhouse. The Koya slaughterhouse cow tallow may consider low cost renewable feed stock to produce biodiesel. Furthermore, the study has examined various process parameters for example, catalyst amount and alcohol amount as well on fuel production yield. The produced biodiesel is also subjected into several tests for instance, density and cetane number.
\end{abstract}

Keywords: Biodiesel, biofuel, renewable energy, cow tallow, process optimization, flash point

\section{Introduction}

Biodiesel could be considered one of the most important sustainable energy in recent decade and future as well. It could be considered as an alternative fuel for diesel engines. Indeed, many oil reservoirs are depleted every day. Moreover, petroleum diesel engines are emitted huge amounts of greenhouse gases every moment that contributed in global worming phenomenon (Alptekin \& Canakci, 2010), (Balat \& Balat, 2010). Therefore, many researchers and oil companies tried to find out new energy sources that can be used as alternative fuel for various uses. Indeed, biodiesel received 
huge attention worldwide to be used as alternative fuel for delis engines. Moreover, it possesses several advantages over petroleum delis for example, reduces the demand of petroleum fuels, nontoxic and reduces the global climate changes and environmental pollution. Furthermore, it has many advantages compared to diesel fuel as it has higher cetane number than diesel fuel, contains no aromatics, almost no sulfur and 10-12\% oxygen by weight. Biodiesel fuelled engines produce less $\mathrm{CO}, \mathrm{HC}$ and particulate emissions than petroleum diesel fuelled engines. Indeed, biodiesel could be used directly in some specific delis engines (Marulandab, Tavlaridesa, 2010), (Shin \& Hun Ryu, 2012). However, it should be blended with petroleum diesel, if it required to be used in normal delis engine. As a result, biodiesel blends can be used in diesel engines without any major modification. Many researchers have indicated that the biodiesel is quite close to diesel fuel. Indeed, biodiesel could be produced from vegetable oils and animal fats as well. Moreover, almost biodiesel is produced from rapeseed oil and waste cooking oil (Alptekin \& Canakci, 2010), (Chakraborty \& Sahu, 2014), (Marulandab, Tavlaridesa, 2010). By using high quality virgin oils makes biodiesel more expensive than diesel fuel (Balat \& Balat, 2010). Indeed, it is quite important to use low cost t feedstock are needed. Moreover, the use of vegetable oil leads to shortage of food while use of animal fat for human consumption is a health hazard (Balat \& Balat, 2010). Indeed, biodiesel could be produced by transesterification reaction that is a three step reversible reaction that converts the initial triglycerides into a mixture of Fatty acid methyl ester and glycerol in the presence of a catalyst usually homogeneous or heterogeneous. alcohol for example, ethanol and methanol can be used in the transesterification reaction (Ahmad, 2012), (Scragg, 2009). Furthermote, several types could be utilized in this reaction for example, sulphuric, hydrochloric acid and sodium hydroxide and potassium hydroxide (Panneerselvam \& Parthiban, 2011). Indeed, acid catalyst is quite slow to be suitable for converting effective at converting free fatty acids to esters. Moreover, animal fats and restaurant waste oils are appealing feedstock to produce biodiesel. Indeed, if the free fatty acid level is less than $15 \%$ it is called yellow grease and if it is above $15 \%$ it is called brown grease (Balat \& Balat, 2010). Moreover, the cost of virgin vegetable oil is about two times more than that of animal fat. Therefore the price of feedstock can be reduced about 50\% with using low grade animal fat (Balat \& Balat, 2010), (Panneerselvam \& Parthiban, 2011). Moreover, in some cases animal fats could be obtained for free at slighter houses. Moreover, they usually content significant amounts of free fatty acids (Ahmad, 2012), (Scragg, 2009). The fats with high FFA cannot be converted to biodiesel using alkaline catalysts which have been used with good results for vegetable oils (Panneerselvam \& Parthiban, 2011). The free fatty acids react with an 
alkaline catalyst and thus soaps are produced. Therefore, optimization of the transesterification reaction has investigated with different methanol/oil ratio and catalyst amount. The obtained ester was characterized by determining its fuel properties according to standard test methods.

\section{Experimental Work}

The cow tallow has been obtained from the local slighter house at Koya city in Iraqi Kurdistan region.

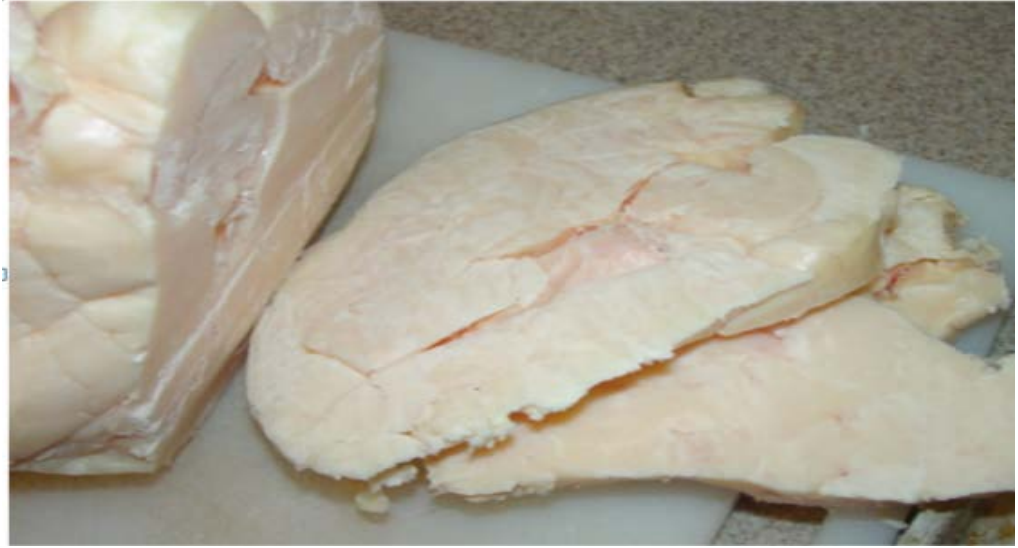

Figure 1: The obtained cow tallow.

Moreover, the fat has been washed and cleaned with deionized water. Moreover, the solid fat has been melted at $(65-70){ }^{\circ} \mathrm{C}$ (Dominik and Janssen, 2007). The melted fat has been filtrated to remove any suspended particles and impurities. Indeed, many researchers have indicated that the preesterification step is not needed if the acid value is lower than $2 \%$ (Panneerselvam \& Parthiban, 2011). Therefore, the preesterification step has been ignored because the acid value of the melted fat is below $2 \%$. Hence alkali was used for th transesterification of Cow fat. Moreover, the experiment has achieved in a laboratory. After Heating and Filtration $150 \mathrm{ml}$ oil, pour it into a $250 \mathrm{ml}$ beaker. Figure (2) shows some of laboratory tools that have been adopted in this project. 


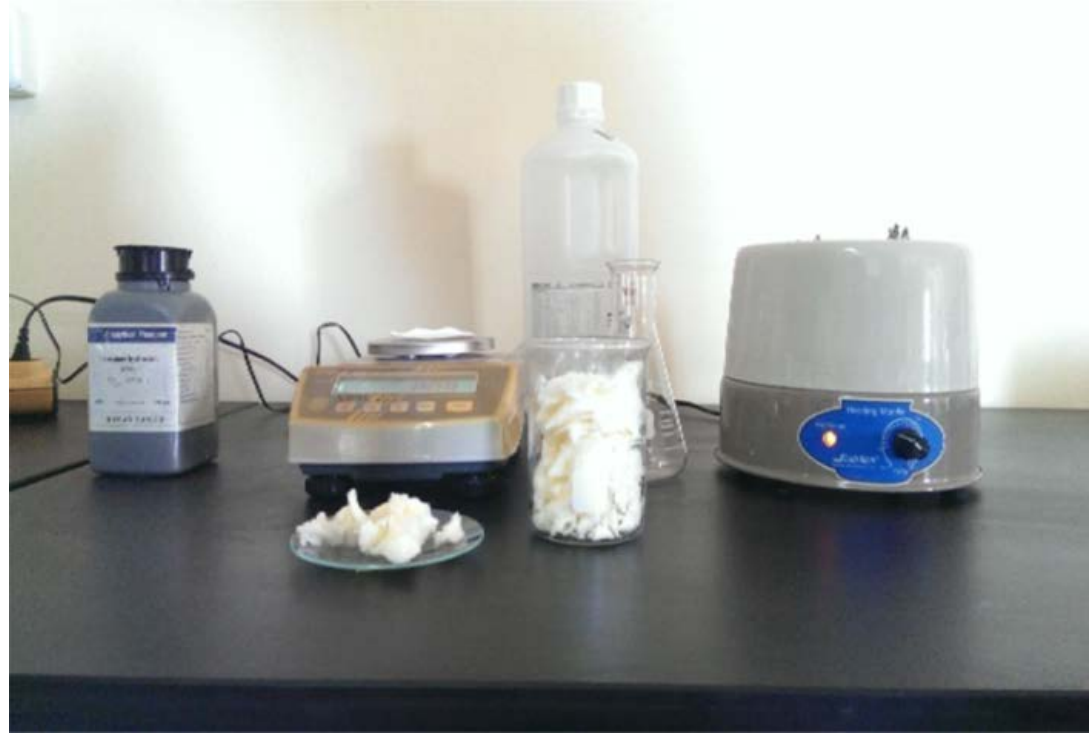

Figure 2: Shows some of laboratory tools that have been adopted in this project.

Heat oil using magnetic stirrer to $120^{\circ} \mathrm{C}$ to remove water and then leave it to reach $60^{\circ} \mathrm{C}$, this temperature keeps the methanol below its boiling point temperature.

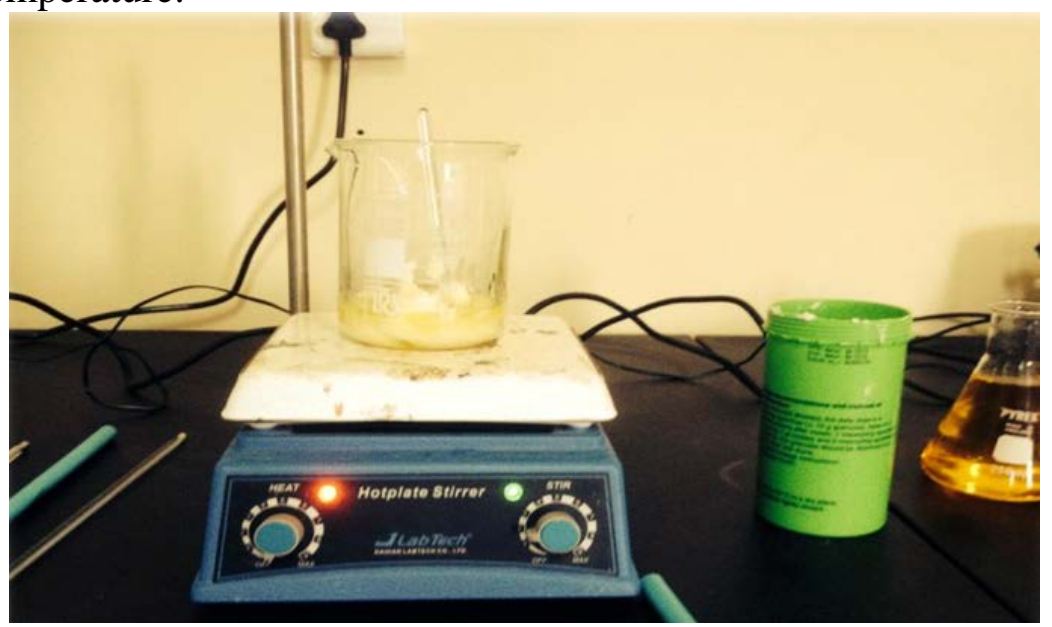

Figure 3: Hot plate magnetic stirrer

Add $40 \mathrm{ml}$ methanol to cylinder, weight 4 grams of $\mathrm{KOH}$ and should be weight it quickly and Pour methanol into $\mathrm{KOH}$, Allow the $\mathrm{KOH}$ to completely dissolve in the methanol. Add Methoxide to the oil. And mixing it by mixture to $25-30$ minute at $60^{\circ} \mathrm{C}$, Alkali transesterification reaction has been adopted to produce the biodiesel from meted fat, and then pour the mixture into a Funnel separator. The mixture should separate into two layers biodiesel and glycerin. After settling for several hours two materials has been 
separated from each other. At the bottom of separator, a red color that content the impurities and glycerol. The esters obtained at the upper layer of the separator funnel. drain off glycerin carefully. And be sure during draining the top rubber is removed to avoid bulb formation you can using it to make soap instead of wasting it. After draining out glycerin, add deionized water to the separating funnel. To get rid of any residues of glycerin and $\mathrm{KOH}$, and then heating it to $110^{\circ} \mathrm{C}$ to remove the water.

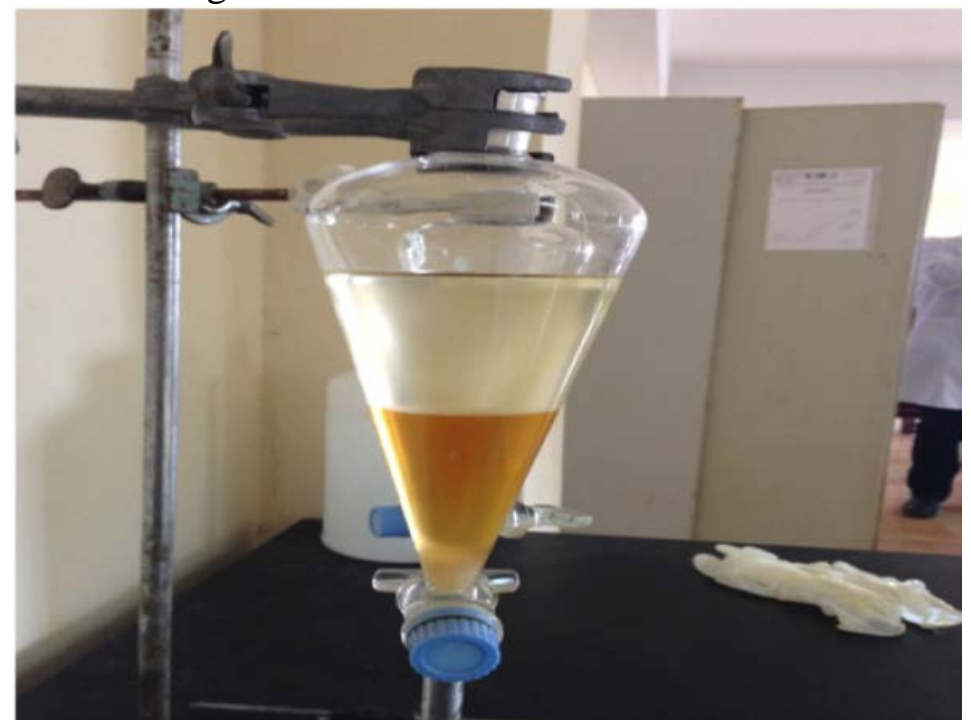

Figure 4: Separation Biodiesel and Glycerin by Funnel Separator.

\section{Properties of Produced Biodiesel}

Transesterification reaction has been achieved by utilizing a cow fat sample. Moreover, this process is achieved yield about $86 \%$. Table 1 shows some physical properties of biodiesel.

Table 1: Physical Properties of produced biodiesel.

\begin{tabular}{|c|c|c|}
\hline Properties & Produced biodiesel & $\begin{array}{c}\text { Standers for Biodiesel } \\
\text { EN14214 }\end{array}$ \\
\hline Density $15^{\circ} \mathrm{C} \mathrm{kg} / \mathrm{m}^{3}$ & 872 & $860 / 900$ \\
\hline Viscosity $40^{\circ} \mathrm{Cmm}^{2} / \mathrm{s}$ & 5.4 & $3.5-5.0$ \\
\hline Cetane Number & 63 & $51 \mathrm{~min}$ \\
\hline Flash point ${ }^{\circ} \mathrm{C}$ & 164 & $101 \mathrm{~min}$ \\
\hline
\end{tabular}

\section{Research methodology}

The cow fat has been obtained \& collected from a local butcher shop at Koya city in Iraqi Kurdistan region. Moreover, the fat has been washed and cleaned with deionized water. Moreover, the solid fat has been melted at (65 -70) ${ }^{\circ} \mathrm{C}$ (Dominik and Janssen, 2007). The melted fat has been filtrated to remove any suspended particles and impurities. Indeed, it quite important 
to determine the free fatty acid (FFA) of the chicken fat in order to uses the accurate catalyst amount at the transesterification reaction. Furthermore, the free fatty acid (FFA) has been determined and found to be $1.8 \mathrm{mg}$ of $\mathrm{KOH} / \mathrm{gm}$ of the chicken fat. Indeed, many researchers have indicated that the prettification step is not needed if the acid value is lower than $2 \%$ (Panneerselvam \& Parthiban, 2011). Therefore, the pre-esterification step has been ignored because the acid value of the melted chicken fat is below $2 \%$. Hence alkali was used for the transesterification of chicken fat. Moreover, the experiment has achieved in a laboratory that considered of $250 \mathrm{ml}$ flasks. The flasks were kept in a water bath maintained at $60^{\circ} \mathrm{C}$. This temperature keeps the methanol below its boiling point temperature. Alkali transesterification reaction has been adopted to produce the biodiesel from meted chicken fat. The calculated amount of $\mathrm{KOH}$ has been dissolved with the needed amount of methanol. This liquid has been poured into the melted chicken fat in a specific flask. The reaction has been done at $60^{\circ} \mathrm{C}$ and for 30 min (Panneerselvam \& Parthiban, 2011). After the reaction was completed for melted chicken fat, the reaction mixture was allowed to be separated into two layers by using a separator funnel. After a wile of time, tow materials has been separated from each other. At the bottom of separator, a red color that content the impurities and glycerol. The esters obtained at the upper layer of the separator funnel. Then, the produced biodiesel has been washed tow times by hot water.

\section{Batch process optimization}

Indeed, the methanol/oil ratio may consider one of the most important parameters that affect the reaction and biodiesel yield. Therefore, the process optimization for biodiesel production has been achieved by adopting several methanol/ oil ratios.

Figure 5 shows the relationship between several methanol/ oil ratios and the yield percent of the biodiesel. It seems from figure 1 that the yield percentages increase by increasing the amount of methanol. However, the reaction reaches equilibrium at methanol/oil ratio about $7: 1$. It also seems from figure 1 that the maximum conversation to ester could be achieved at methanol: oil ratio about 7:1. As a result, it could be argued that adopting molar ratio of methanol/oil ratio between $(6: 1$ to $7: 1)$ could achieve the optimal molar ratio. 


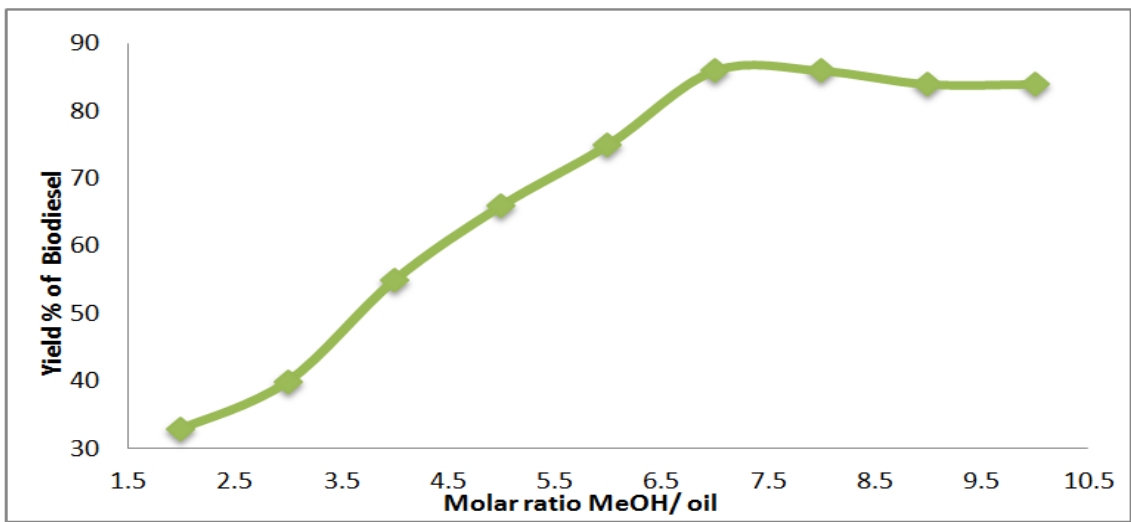

Figure 5: The relationship between the molar ratio of $\mathrm{MeOH} /$ oil and biodiesel yield\%.

In this study $\mathrm{KOH}$ has been obtained as a catalyst. Indeed, catalyst amount is also an important process parameter. Therefore, the process is also optimized by adopting several catalyst amount with a range between $(0.34-$ 0.4) gms of $\mathrm{KOH}$ and the molar ratio of $\mathrm{MeOH} /$ oil molar ratio 7:1. Figure 2 shows the relationship between several $\mathrm{KOH}$ catalyst amounts and the ester yield percentage. It seems from figure 6 that the reaction could be achieved in all catalyst amounts. However, the adopting of $\mathrm{KOH}$ amount about 0.38 gm could achieve high ester yield about 86\%. Moreover, the increasing of catalyst amount above 0.38 gm may decrees the reaction yield.

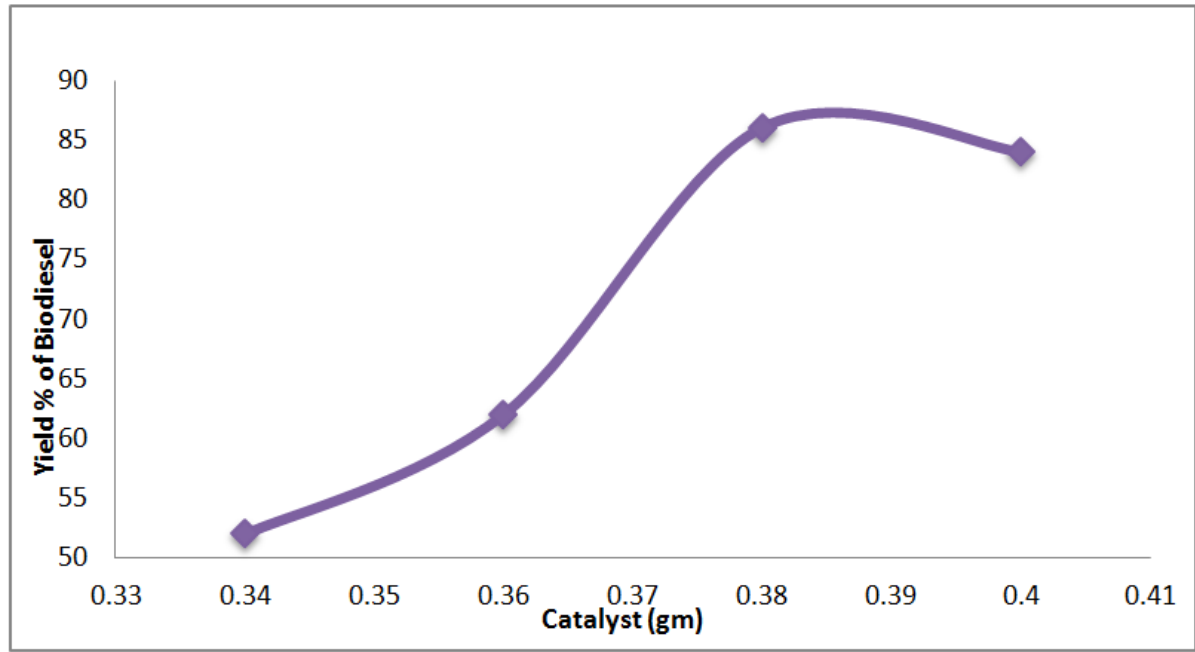

Figure 6: The relationship between the amount of catalyst and biodiesel yield\%.

\section{Conclusion}

This study is attempted to investigate and produce biodiesel from cow's tallow. It can be argued that it possible to produce biodiesel from cow's tallow by adopting transesterification reaction method. Therefore, it recommended that utilizing waste fats at Koya city slaughterhouse as a 
promised feedstock for biodiesel production. Moreover, the process optimization is also achieved for several process parameters for example, catalyst amount \& amount of methanol. It could be argued that adopting methanol/ oil ratio about 7:1 could achieved good biodiesel yield about $86 \%$. Moreover, it could be also argued that using $0.38 \mathrm{gm} \mathrm{KOH}$ catalyst could achieved good biodiesel. As a result, any additional excess catalyst could lead to reduction in ester yield. Furthermore, the biodiesel production could be incomplete if the methanol amount is less than the optimal value.

\section{References:}

Alptekin, E. \& Canakci, M. (2010) 'Optimization of pretreatment reaction for methyl ester production from chicken fat', Fuel. 89 (1), PP. 4035-4039. Chakraborty, R. \& Sahu, H. (2014) 'Intensification of biodiesel production from waste goat tallow using infrared radiation: Process evaluation through response surface methodology and artificial neural network', Applied Energy. 114 (1), PP. 827-836.

Balat , M. \& Balat, H. (2010) 'Progress in biodiesel processing', Applied Energy. 87 (1), PP. 1815-1835.

Chena, C., Chena, W.,Changa, C., Ming Lai, b., \& Hsiun Tuc , C. (2010) 'Biodiesel production from supercritical carbon dioxide extracted Jatropha oil using subcritical hydrolysis and supercritical methylation', The Journal of Supercritical Fluids. 52 (2), PP. 228-234.

Marulandab, V., Anitescua, G. \& Tavlaridesa, L. (2010) 'Investigations on supercritical transesterification of chicken fat for biodiesel production from low-cost lipid feedstocks', The Journal of Supercritical Fluids. 54 (1), PP. 53-60.

Shin, H., Lee, S. \& Hun Ryu, J (2012) 'Biodiesel production from waste lard using supercritical methanol', The Journal of Supercritical Fluids. 61 (1), PP. 134- 138.

Balat , M. \& Balat, H. (2010) 'Progress in biodiesel processing', Applied Energy. 87 (1), PP. 1815-1835.

Ahmad, M. (2012) Practical Handbook on Biodiesel Production and Properties. Boca Raton: CRC Press.

Scragg, A. (2009) Biofuels: Production, Application and Development. Oxfordshire: CABI co.

Panneerselvam, I. \& Parthiban, R. (2011) Poultry Fat: A Cheap and Viable Source for Biodiesel Production. 2nd International Conference on Environmental Science and Technology. Singapore, Monday 18th to Wednesday 20th February 2011. Singapore: PubM. pp. 42-45.

Dominik R, and Janssen, R. (2007) Biofuel Technology Handbook. 